\title{
VIDAS DE MENTIRA: FUNCIONES SUSTITUTIVAS Y SIMBÓLICAS DE LAS MUÑECAS EN ALGUNOS EJEMPLOS DE NARRATIVA HISPÁNICA
}

\author{
Vicente Luis MORA
}

Universidad de Estocolmo

\begin{abstract}
—Deténgase vuesa merced, señor don Quijote, y advierta que estos que derriba, destroza y mata no son verdaderos moros, sino unas figurillas de pasta.
\end{abstract}

Miguel de Cervantes, Quijote, II (1994: 825)

Me acuerdo de que, en la residencia de los propietarios de una apartada finca rusa, vi, en manos de los niños, una vieja muñeca que se parecía a toda la familia.

Rainer María Rilke (1999: 26)

Desnudar lo que un día fue un hombre y extraer a la luz y a las tinieblas un muñeco de trapo.

Eduardo García (2017: 385)

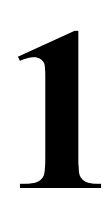

\section{Antecedentes}

El simulacro subjetivo, una de las formas características de la disolución del sujeto en la literatura, es una tendencia histórica de largo recorrido cultural y antropológico, presente en diversas latitudes. René Girard denomina «hipótesis de la sustitución» a una suerte de dobles sociales que existen en algunas culturas. Por ejemplo, en la africana tribu dinka los antropólogos han descrito «una auténtica sociedad bovina, paralela a la sociedad de los hombres y estructurada de la misma manera», que llega a «constituir un auténtico doble de la sociedad humana» (1983: 11). La literatura hispánica actual (entendiendo por tal, desde una perspectiva transatlántica, la hispanoamericana y la peninsular) acoge asimismo dobles sociales a partir de simulacros de identidades individuales socializadas, volcando en la descripción subjetiva valores colectivos, tomados sub aespecie universalis. Hay otros simulacros identitarios, como los avatares o los pseudónimos digitales, pero hoy queremos referirnos a figuras de sustitución subjetiva más específicas presentes en cierta narrativa actual, donde las muñecas cumplen, como veremos, tres funciones básicas: la idealización, la cosificación y la simbolización. También exploraremos posibles razones de esa extraña abundancia de muñecas en la literatura contemporánea. 
Una de las formas sustitutivas más antiguas y frecuentes es la creación de formas antropomorfas sobre las que se proyecta la vida; admiten numerosas variantes, entre ellas los autómatas o figuras «animadas», como la Pandora clásica o la estatua viviente de Pigmalión, a los que sus creadores dotan de ánima, de alma; los muñecos, sobre los que se centrará este texto; los golems; las marionetas tratadas por Heinrich von Kleist en Sobre el teatro de marionetas (1810), los maniquíes parisinos de Karl Huysmans y Walter Benjamin, citados por este último en la sección «El muñeco, el autómata» de El libro de los pasajes (2005: 701-707)¹; el Frankenstein de Mary Shelley, y, más tarde, los zombis (véase Fernández Gonzalo), para terminar en los androides y robots inteligentes o animados por inteligencia artificial, interminablemente presentes en novelas, películas o series televisivas. En todos estos casos las efigies matéricas «cobran vida», o se proyectan sobre ellas valores humanos, personificándolas. En este texto nos centraremos específicamente en las muñecas, que tienen luenga tradición literaria, pero que han cobrado en los últimos diez años una singular presencia en ambas orillas de la narrativa hispánica, presencia creciente en la que intentaremos ahondar.

Conviene asomarse a algunos ejemplos de la tradición, para mostrar la naturaleza sustitutiva y alegórica de las figurillas. En su obra de teatro Las muñecas de Marcela (1634), Álvaro Cubillo de Aragón se imagina la habitación de Marcela, donde ésta guarda diversas muñecas de tamaño natural. Carlos, un caballero que huyendo de una liza se ha colado a través del tejado, y Beltrán, su acompañante, se esconden en los aposentos de Marcela para evitar una venganza. Allí Beltrán imagina que pueden hacerse pasar por muñecos masculinos, compañeros de las muñecas de doña Marcela:

Somos figuras supuestas;
muñecos somos, que viendo
que estaban aquestas hembras,
a fuer de amazonas, solas,
vinimos a estar con ellas.
¿No le ve usted que no habla?
Ni yo, aunque se lo parezca,
tampoco hablo, que todo
es obra de ropa vieja;
de puro retal de sastre
nos hizo una muñequera.
Todo cuanto ve es andrajos,
narices, ojos y cejas,
puntadas de hilo prieto

(Cubillo, 2016).

En 1816, E. T. A. Hoffmann crea en su conocido relato «El hombre de arena» a Olimpia, una muñeca tan real que enamora a su vecino de enfrente, quien la ve a través de la ventana. Como es sabido, Sigmund Freud parte precisamente de este relato y de la efigie de Olimpia para construir su teoría sobre lo siniestro en su ensayo «Das Unheimliche». En él recuerda Freud que E. Jentsch había destacado, «como caso por excelencia de lo siniestro, la "duda de que un ser aparentemente animado, sea en efecto viviente; y a la inversa: de que un objeto sin vida esté en alguna forma animado"»,

\footnotetext{
${ }^{1}$ En cierto momento recuerda Benjamin: «Cuando Víctor Hugo escribía Los trabajadores del mar, tenía ante sí un muñeco con el traje antiguo de una dama de Guernesey» (2005: 703).
} 
aduciendo con tal fin, la impresión que despiertan las figuras de cera, las muñecas «sabias» y los autómatas, añadiendo que uno de los recursos literarios más inquietantes «consiste en dejar que el lector dude de si determinada figura que se le presenta es una persona o un autómata» (Freud, 2005: 667). Patrick J. Gyger recuerda otro clásico de la literatura fantástica, La Eva futura (1886), de Auguste Villiers de l'Isle-Adam, donde «el personaje principal, creyendo encontrar en la réplica mecánica de su prometida la solución a sus problemas sentimentales, se enamora de ella a pesar de haber participado él mismo en su concepción» (2009: XI-XII; para Pilar Pedraza el de Villiers es «uno de los textos más misóginos de todos los tiempos», 2012: 143), y cabría añadir los soldaditos de plomo de Andersen y a las figurillas de barro que una figura diabólica da vida para luego triturarlas en El forastero misterioso (1916) de Mark Twain. Los textos sobre réplicas humanas comienzan a ser una constante, sobre todo desde el Romanticismo, ligadas al auge de la literatura fantástica, y de ese legado o suelo brota Puppen (1921) de Rainer María Rilke, un texto sobre muñecas en el que según Daniel Mesa Gancedo, Rilke

[...] encontró nuestra manera especial de ser en ese objeto particular que es la muñeca: concebirla como "tubo de ensayo" ("Probeglas", probeta ímproba, matraz que, claro, es matriz) del ser es un hallazgo que debe ser tenido en cuenta en cualquier reflexión sobre la otredad (1999: 23).

Quizá esto se podría conectar con el caballito de cartón del poema «Un niño que soñaba» de Antonio Machado (1972: 63), o con la muñeca autómata Francine que, según se cuenta, construyó o mandó construir René Descartes para sustituir a su hija muerta, Francine (véase Bueno y Peirano 2009: 32). Esto trae al recuerdo a la «muñeca tridimensional de tamaño natural a imagen de su amante» (Kandel, 2013: 178), que Oscar Kokoschka fabricara de Alma Mahler, después de su ruptura, o a la réplica de Hércules que construyese Dédalo y que movió al semidiós a golpearla, pensándola viva (Apolodoro 1985: 121).

Como iremos viendo, las muñecas pueden desarrollar diferentes funciones en las ficciones, incluso la de convertirse en símbolos para transmitir, a través de los niños, problemas de los adultos, como los conflictos de género y políticos. Así sucede en la película Imitation of Life (1959), de Douglas Sirk, donde Susie, hija de blancos, está jugando con Sarah Jane, mulata y casi blanca, como se sugiere en algún momento de filme. Cuando Susie le tiende una muñeca afroamericana, Sarah Jane la tira al suelo y le pide a Susie una muñeca blanca para jugar. El gesto de arrojar el muñeco al suelo acrecienta la sensación de extrañamiento, pues, como recordaba Agamben, pocas cosas producen tanta inquietud como el juguete infantil que ha perdido su función:

Y nadie sabe mejor que los niños cuán atroz e inquietante puede ser un juguete, cuando el juego del que formaba parte ha terminado. El instrumento de liberación se convierte, entonces, en un torpe trozo de madera, la muñeca sobre la cual la niña ha vertido su amor, en un gélido y vergonzoso muñeco de cera, que un malvado mago puede capturar y hechizar para servirse de él en contra de nosotros (2005: 113-14).

Esa pérdida de la función objetual puede ser una metáfora del deseo perdido, como sucede en el poema «Life Story» de Tennesse Williams, donde los dos amantes por la mañana se encuentran «like a pair of rag dolls a bored child dropped on a bed» (2007: 52; el poeta y narrador José Ángel Cilleruelo recoge y traduce en Barrio Alto este verso de Williams, 1997: 68). Las muñecas también pueden servir 
para intensificar un sentimiento concreto, gracias al efectismo, como en este párrafo de Svetlana Alexiévich:

Hablan los militares. Un general ha perdido la palabra... Las mujeres de negro lloran. La gente guarda silencio. Tan solo una niña pequeña con trenzas se ahoga en sollozos junto a uno de los ataúdes: '¡Papá! ¡iPapááá!! ¿Dónde estás? Me prometiste que me traerías una muñeca. ¡Una muñeca bonita!' (2016: 21).

O para representar plásticamente el entendimiento de la ciudadanía con muñecos autómatas, como describía Descartes en El discurso del método y se aprecia en este irónico texto de A quien corresponda (2008), del argentino Martín Caparrós:

Alguien me contó que hay un juego de computadora que se llama Civilización donde sos un muñequito cavernícola que tiene que tomar una serie de decisiones... y termina por construir una sociedad como la egipcia o la romana; pensé que podrían hacer otro juego que se llamara Argentina donde, si el muñequito patriota de mayo toma todas las decisiones equivocadas -pero todas, sin confundirse ni una vez-, termina por construir este país (2008: 136-37).

Otras veces cobran la forma de mero fetiche (Ory, 1975: 137) o de residuo melancólico de la infancia (así en el chileno Adolfo Couve, 2003: 458; o en el argentino Bruno Galindo, 2012, 24).

\section{Las muñecas como simulacros subjetivos en la literatura hispánica}

No recuerdo día de más emoción que ese, pasado junto a la muñeca de cera revestida con un traje de raso. La noche se llenó de algo fúnebre y palpitante.

Ramón Gómez de la Serna (1986: 586)

Una de las formas de la reduplicación subjetiva no en lo textual, sino en lo matérico, a través de la construcción de una réplica o imagen, se ve potenciada en nuestros días gracias a la tecnología del plástico, que permite una precisión reconstructiva sin parangón con las posibilidades técnicas anteriores. El arte, sin embargo, recupera para su ámbito ese potencial simulacral: amén de las esculturas hiperreales de Charles Ray (véase Guasch, 2000: 513) o Ron Mueck, la literatura vuelve a utilizar el motivo del doble corporal a través de la muñeca pornográfica, la muñeca hinchable o de plástico que imita a un natural concreto, revelando la pulsión de necesitar una copia del cuerpo deseado sobre la que operar, luego veremos ejemplos de los narradores españoles Juan Francisco Ferré y Ramón Buenaventura. En estos supuestos la muñeca cumple el papel de representar plásticamente (en ambos sentidos de la palabra) la perversión de alguno de los personajes, mediante el simulacro de un «objeto artificial» (Aumont, 1992: 107) sustitutivo.

En otros casos, muñecos de otros tipos cumplen la función simulacral, como sucede en la última parte de la narrativa de la española Mercedes Cebrián; en La nueva taxidermia (2011), de la que luego volveremos a hablar, la reduplicación del simulacro identitario viene configurado por los muñecos de ventriloquía, mientras que en El genuino sabor (2014) se vertebra de un modo -significativamentecomercial, a través de una empresa: la que tiene Janet, uno de los personajes secundarios, «cuya misión es contratar a dobles de la familia real británica para que animen fiestas y eventos públicos» (2014: 
73). En Limbo (2014), de Agustín Fernández Mallo, la reduplicación de personas, identidades y objetos es uno de los elementos principales de la trama, sustentada sobre el entrelazamiento cuántico que permite que una cosa sea otra en distintos estados y lugares, pero también que dos cosas o personas distintas sean, puntualmente, la misma. La autora argentina Fernanda García Lao, en su novela Fuera de la jaula (2014), describe cómo un personaje, Domingo, intenta transformar a su mujer, Aurora, la narradora de la primera parte de la novela, en la actriz Lana Turner (del mismo modo en que John Ferguson/James Stewart intenta en Vértigo,1958, de Hitchcock convertir a Judy/Kim Novak en la desaparecida Madeleine; un desarrollo de trama similar, vía la cirugía estética, puede encontrarse en L. A. Confidential, 1997, de Curtis Hanson). Cuando no lo consigue, Domingo fabrica una réplica mecánica de la misma, muy fiel a la Turner original, con la que tiene relaciones sexuales, dejando de lado a Aurora (2014: 61 y ss). En Brilla, mar del Edén (2014), de Andrés Ibáñez, un ingeniero construye a su mujer ideal, Ariko, un androide de última generación, capaz de amar. Los mitos sustitutivos se reactualizan mediante el simulacro y no pierde vigor con el paso de los siglos, animados siempre por el estímulo del desarrollo de las tecnologías de vida artificial.

\section{Simbolización en Rosario Ferré}

La puertorriqueña Rosario Ferré incluyó en su libro de relatos Papeles de Pandora (1976) el relato «La muñeca menor», en el que la narradora describe a su tía, una extraña mujer que fabrica muñecas y que sufre en su pantorrilla la presencia huésped de una chágara o cangrejo de río, que años atrás se le quedó incrustada y que vive alojada en su interior. La autora construye la narración en dos planos: uno viene constituido por la presencia de un animal cenagoso en el interior de un cuerpo; el segundo, por la presencia, también huésped, de las muñecas que va fabricando la tía para sus sobrinas:

Con el pasar del tiempo fue refinando su arte hasta ganarse el respeto y la reverencia de toda la familia. [...] La tía había ido agrandando el tamaño de las muñecas de manera que correspondieran a la estatura y a las medidas de cada una de las niñas. Como eran nueve y la tía hacía una muñeca de cada niña por año, hubo que separar una pieza de la casa para que la habitasen exclusivamente muñecas (2002: 200).

Cuando la hija menor abandona la familia, tras su casamiento con un joven médico, decide llevarse consigo su muñeca, que tenía engastadas dos joyas brillantes en cada ojo. El avaro médico extrae las piedras preciosas con un bisturí, y tras esa pérdida de valor la joven comienza a reproducir posturalmente a la muñeca, lo que afecta también a la lozanía de sus ojos, que se vuelven tristes y caídos, al haber sido privados del brillo de las joyas. Con el paso de los años el médico crece y envejece, pero su mujer mantiene su juventud y su piel «aporcelanada» (2002: 204). El final del relato, donde las dos amenazas huésped se unen, es previsible:

Una noche decidió entrar en su habitación para observarla durmiendo. Notó que su pecho no se movía. Colocó delicadamente el estetoscopio sobre su corazón y oyó un lejano rumor de agua. Entonces la muñeca levantó los párpados y por las cuencas vacías de los ojos comenzaron a salir las antenas furibundas de las chágaras (2002: 204). 
Como recuerda Vania Bazarra, el simbolismo del relato ha provocado que haya sido interpretado de distintas formas; «los análisis interpretan la historia como: "una metamorfosis o fusión de la sobrina menor en una muñeca"» (2010: 81), lo que, según Bazarra, concluyen Umpierre, Guerra-Cunningham, Roses, Rivera o Erro-Peralta, «o como una extensión de su autora a través de la creación de un doble vengativo que sustituye a la sobrina como referente [...], es decir, un intercambio o "canje mágico entre la muñeca y ella misma” (Gutiérrez 31)» (Bazarra, 2010: 81). La conclusión a la que llega Bazarra es que «el regalo de bodas de la muñeca menor es un maquillaje, un simulacro que permite transmitir una frustración contenida por años», añadiendo que «la tía [...] realiza un acto de venganza para reparar un agravio cometido en contra de la cosificación y manipulación de la mujer transformada en objeto de decoración artificial» (2010: 85). El simulacro subjetivo produce, en estas circunstancias, un simulacro de las pulsiones contenidas.

Otro ejemplo, español en este caso, es el ya citado de Mercedes Cebrián en «Voz de dar malas noticias», nouvelle incluida en La nueva taxidermia. Es la novela de una chica, Belinda, una ventrílocua que comienza a hablar sólo a través de tres muñecos; más tarde reúne las propiedades de los tres en una copia pequeña y exacta de sí misma, llamada Minibelinda, que acaba ocupando por completo su personalidad. La misma autora, en su último poemario, Malgastar (2016), escribe: «Qué susto si las cajas se abren a la vez, / si el muñeco de muelle nos salta hacia los ojos» (2016: 38). Dentro de los relatos de Patricia Esteban Erlés en Casa de muñecas (2012) hay un microrrelato, titulado «Otra», en el que la autora utiliza la imagen de la muñeca para criticar inteligentemente los excesos de la cirugía plástica, que acaban convirtiendo en muñecas de plástico a las mujeres excesivamente operadas:

En San Valentín me regaló dos tetas, que sostienen impertérritas la mirada a la odiosa ley de la gravedad. Por mi cumpleaños llegaron unos pómulos, lisos y esteparios. Encontré una melena de muñeca muerta al pie del árbol, las últimas navidades. Son tus nuevas extensiones de pelo natural, querida, cuestan un riñón, me dijo. Salen juntos, beben y se divierten, él y ella. Yo me echo mucho de menos. (2012: 72)

En estas circunstancias, la protagonista de Esteban Erlés, víctima del «residuo biopolítico» (Byung-Chul Han, 2014: 42) de la cirugía plástica, cae dentro del régimen de El hombre postorgánico (2005), planteado por Paula Sibilia, en el que la silicona convierte la identidad en tecnociencia (2006: 70). También podemos citar los muñecos diseñados por uno de los inquietantes personajes de la novela de Paula Lapido Horror vacui (2015), que dice que su máxima vital es «reproducir la naturaleza» (2015: 98). Germán Sierra plantea en Efectos secundarios (2000) la posibilidad de reproducir a personajes famosos como muñecos a escala natural, mientras que ensu última novela hasta la fecha, Standards (2013), Sierra presenta una especie de distopía en la que se duplican mujeres mediante la programación genética. En Muñecas (2008), del argentino Ariel Magnus, el protagonista convive con seis muñecas hinchables, algunas de las cuales menstrúan; para Héctor Hoyos, que ha examinado la novela de Magnus desde la perspectiva de la cultura material, «Muñecas habla sobre los riesgos y placeres de la cosificación, y se plantea la pregunta por un nuevo morar entre cosas y humanos» (2016: 462). También encontramos una pequeña mención figurativa en Alan Pauls; para Teresa Oreccia, «En Historia del llanto esa mirada está siempre atenta al surgimiento del ridículo, a la detección de lo 
mecánico y lo artificial, y así identifica como muñecos animados a los militares impecables con los que el niño se cruza en su barrio»(2016: 338). Y habría otros tratamientos que podrían revisarse, como el relato «La muñeca reina» de Carlos Fuentes (en Cantar de ciegos, 1964), Último round(1969)de Julio Cortázar, los relatos de Silvina Ocampo «Los funámbulos» (en Viaje olvidado, 1937) y «La muñeca» (en Los días de la noche, 1970) y alguna mención puntual en otros autores como las mexicanas Nellie Campobello (Cartucho, 1931) y Delfina Careaga (La muñeca vestida de azul, 1975, llevada al cine por Arturo Ripstein en 1978, con el título La tía Alejandra), o el español Miguel Sánchez-Ostiz (14). Y los ejemplos, de por sí numerosos, serían incontables si hiciéramos mención a la figura de las muñecas rusas (véase Deleuze 18), tan habitual en la metaliteratura (Millás, 2008: 24 25), pero que no forma parte de nuestro estudio.

\section{Algunos ejemplos de cosificación}

Si en los casos anteriores estábamos ante formas asimilables a los dobles sociales que veíamos con Girard, ahora entramos en supuestos más específicos, relacionados con sustituciones o suplementos sexuales de corte reificador. Providence (2009), la novela de Juan Francisco Ferré, se abre con una escena sexual que involucra a su protagonista Álex Franco con una mujer, Delphine, y la réplica en plástico de ésta. En la novela de Ferré podemos leer que la muñeca

Era una copia perfecta de Delphine inmortalizada en plena juventud. Una muñeca sintética con sus mismas facciones y atributos carnales. El maniquí desnudo era ella, o una imagen congelada de ella, con cuarenta años menos, según me dijo con humor, pero la misma cantidad de kilos (cincuenta y cuatro), sin un gramo de grasa sobrante. ... La doble estética de Delphine había sido diseñada y pagada al contado por un amante maniático cuando ella tenía veinteaños, un productor de cine mucho mayor que ella, ya muerto, que no soportaba la idea de verla envejecer y perder la belleza que lo había cautivado y se hizo fabricar este simulacro de silicona y látex para eternizarla sexualmente, según me contó poniéndose seria de repente. Delphine soñaba por entonces con llegar a ser una gran actriz y había actuado en algunas películas de éxito moderado (Ferré, 2009: 24-25)

La muñeca, encargada por Robert, ese antiguo amante de Delphine obsesionado con ella, es un caso evidente de cosificación, pues Robert no sólo sustituía a veces a la mujer usando a la copia, sino que a veces llegaba a prostituirla con sus amigos, cuando estaba enojado con Delphine (Ferré, 2009: 26). Aunque para Delphine la muñeca simboliza su juventud perdida, para Álex Franco es algo muy distinto:

[...] la muñeca, con todo su embalsamado poder de seducción, no representaba para mí sino una imagen plástica de su cadáver. Un fetiche fúnebre. Un cuerpo momificado e incorrupto, un simulacro sin vida ni sensibilidad, reconstruido con materiales imperecederos e impecable artesanía funeraria, pero no un cuerpo fragante y deseable, tan maduro para la entrega y el placer como para la muerte y la putrefacción. (2009: 26)

Esta perduración de la belleza a través del simulacro puede recordar al que Ramón Gómez de la Serna, según Roberta Ballestriero, elabora en La sagrada cripta del Pombo ${ }^{2}$. Al final, Alex Franco

\footnotetext{
${ }^{2}$ A juicio de Ballestriero, Gómez de la Serna lleva a cabo, mediante su visión de la muñeca como «mujer ideal» (2016: 103), una operación a medias fetichista y a medias irónica, sin dejar de recordar que Ramón tuvo entre sus muchas y
} 
debe hacer el amor -quizá sea ésa la expresión más adecuada- a la muñeca, porque es la condición que Delphine pone para apoyar su carrera cinematográfica (2009: 27-28). En un giro de doble vuelta muy característico de Ferré, primero se cosifica a la mujer, mediante la creación de la réplica; pero, en un segundo momento, el cosificado es el hombre, pues Delphine, al obligarle a acostarse con la muñeca, consigue seguir manteniendo intacto en su imaginario el atractivo irresistible de su figura joven. Gracias al objeto copia los hombres siguen sucumbiendo al atractivo físico de Delphine, incluso cuando ese encanto ha desaparecido del cuerpo original.

La novela de Ramón Buenaventura NWTY (2013), que sería un ejemplo de estética neobarroca (Calabrese, 1984), o de lo que Francisca Noguerol llama el «barroco frío» (2013: 17-32) dentro de la narrativa española, aborda el asunto también desde el aspecto sexual. En la página 210 incluye una reproducción de la página web de Real Doll, una marca de muñecas de silicona por encargo, a gusto del consumidor. Dos de los cuatro narradores de la novela comentan el juguete sexual, diciendo uno de ellos: «pues yo conocí a una pareja que tenía dos de estos muñecos, uno de mujer y otro de hombre. En Madrid, además» (Buenaventura, 2013: 211). Y luego pasa a describir una escena erótica, en la que León Aulaga (uno de los personajes de una novela anterior de Buenaventura: El año que viene en Tánger,1998) y su pareja acuden a una cena con los propietarios de las réplicas y acaban envueltos en un intercambio de parejas que incluye a la tercera pareja de silicona (2013: 217-222). En este caso el uso de muñecas parece tener un uso más ornamental, aunque queda claro que su uso por la pareja responde a la falta de satisfacción sexual de ella, al estar el personaje masculino impotente por una medicación cardiovascular; es decir, tiene una función sustitutiva de la potencia sexual perdida. La muñeca también expresa aquí una carencia psicológica, que se intenta compensar mediante un simulacro subjetivo.

\section{La casa de muñecas}

Jugar a las muñecas supone la primera performance de tu vida. Diferentes mujeres representando dentro de ti las mismas escenas, renuncias, caídas de párpados.

Erika Martínez (2017: 18)

Un clásico en esta cuestión es la conocida obra de teatro de Ibsen Casa de muñecas (1879), considerada como la primera dramaturgia feminista. En ella Nora se rebela contra el destino prefijado por su familia, y critica el modo en que ha sido tratada como una muñeca por su padre, comportamiento que luego ella ha reproducido con sus propios hijos. De la obra de Ibsen parten el citado libro de relatos de Patricia Esteban, Casa de muñecas, y también el relato «Caza de muñecas», de Marina Perezagua, incluido en Criaturas abisales (2011: 101-109). Este último relato comienza con la quema masiva de

diversas pertenencias una muñeca de cera. Ballestriero cita un significativo párrafo de la obra de Gómez de la Serna, que puede dialogar con el de Ferré: «Es la mujer que sueñan tener los hombres: sin envejecer y rotunda y aparentemente, fresca y bonita. ¡Cómo se irritan con ella las demás mujeres! Tiene orgullo de reina de los juegos florales y de primer premio de belleza, y nos evita ya para siempre la tontería de pretender a una mujer así... [...] Tiene toda la memoria irritante de los requiebros que escuchó, y tiene la serenidad de la que sabe que hay tiempo para todas las infidelidades» (Gómez de la Serna, 1986: 589). 
muñecas en una ciudad innominada, debido al comportamiento de esos «juguetes aberrantes» (Perezagua, 2011: 101). Los padres de esa ciudad habían comenzado a alarmarse cuando «se fueron dando cuenta de que en el cuarto de sus hijas, día sí y día no, había algún muñeco que nadie había visto antes, mientras que, día sí y día no, desaparecía una muñeca que sí era de su hija, que volvía a aparecer al día siguiente acompañada de otro muñeco desconocido, y así sucesivamente» (2011: 103). Este párrafo no sólo da el salto del relato al género fantástico, dotando de alma (y de cuerpo) a las muñecas, sino que también encubre una de las posibles significaciones del relato, la de simbolizar la resistencia de los padres ante los primeros escarceos sexuales de sus hijas, metaforizadas mediante las muñecas que poseen. En el relato, las niñas comienzan a cambiar sus juegos inocentes con las muñecas por escenas sexuales montadas con ellas, tan imaginativas que «en pocas semanas los padres llegaron a tener la sensación de estar aprendiendo de los nuevos juegos de sus hijas» (2011: 105). Lo infantil e inocente se vuelve siniestro, porque, como recuerda Jazmín Acosta en la órbita de Freud, «La apariencia de vida que tiene un muñeco es lo que de él nos resulta siniestro» (2012: 31). En el relato de Perezagua esa percepción de lo siniestro es tan aguda y la situación llega a ser tan generalizada y grave que no sólo se proscriben las muñecas, sino que se eliminan por completo, se cierran los colegios, se aísla a los niños y se les impide crear muñecos o réplicas de efigies con cualquier objeto. Al final los niños se inmovilizan y se quedan rígidos, convertidos, ellos mismos, en muñecos (Perezagua,2011: 108). No está claro si la autora se propone hacer una lectura simbólica del biopoder de los adultos sobre los niños, o una mera metáfora fantástica, pero el resultado es desasosegante, al plantear los resultados sociales de una hipersexualización de los niños. Sexualización que, como ha apuntado Edmundo Paz Soldán, está más presente en nuestros días de lo que pudiera pensarse, precisamente a través de la venta y publicidad de algunas muñecas, como las Bratz (Paz Soldán, 2009:173) o las Barbies (véase el caso de la estadounidense Cindy Jackson, que se ha operado más de treinta veces para parecerse a una Barbie, en Sibilia, 2006: 181).

Una variante de la casa de muñecas sería la tienda de muñecas, lugar de origen del texto de Rilke que volveremos a citar inmediatamente, y también del microrrelato «Infame. Una traición» (2013), de la ecuatoriana María Paulina Briones, que ambienta en una de esas tiendas la perversa historia criminal que envuelve a Claudia y la narradora. En uno de sus párrafos podemos encontrar una forma explícita donde el mundo de las muñecas es como una reproducción a escala del nuestro: «Todo formaba parte del escenario de ese mundo en miniatura dentro de la tienda de muñecas, que reproducía el horror de los juguetes que adornan las estanterías de mi memoria» (2013: 188). Este significativo fragmento da pábulo a una de nuestras interpretaciones de la hiperabundancia de muñecas en la literatura hispánica actual: su relación con la pulsión simulacral típica de nuestra era y su literatura (Gómez Trueba y Morán, 2017). 


\section{El desasosiego existencial}

Luego habría otro tipo de muñecas más metafísico, por decirlo de algún modo, que son las que nos abren las puertas de la falta y la carencia existenciales. El penetrante texto de Rilke ya lo dejaba caer de este contundente modo:

En un tiempo en el que todavía todos se esforzaban por respondernos siempre de forma rápida y tranquilizadora, ella, la muñeca, fue la primera que nos puso delante aquel silencio inconmensurable cuyo soplo sentiríamos llegar más tarde reiteradamente desde el espacio, cada vez que pisábamos algún lugar en el límite de nuestro ser. Frente a ella, mientras nos miraba fijamente, experimentamos por vez primera (¿o me equivoco?) ese vacío del sentimiento, esa parada del corazón en la que uno se extinguiría, si en ese momento la naturaleza entera, prosiguiendo suavemente su marcha, no lo transportase como algo inerte por encima de los abismos (Rilke, 1999: 26).

Me parece ver un ejemplo en la desasosegante novela corta del argentino Ramiro Quintana El intervalo (2006), donde Virgilio, el personaje principal, está encerrado en una habitación de hotel, pasando un «intervalo» de tiempo, suponemos que durante un viaje; en esa habitación pasa las horas, transformando una muñeca en la reproducción exacta de su novia Irupé. Así comienza la novela:

Luego, Virgilio dispone el cuerpo de la muñeca sobre las sábanas de la casa matrimonial. Con afligida precaución, se coloca un par de guantes de látex para cirugía, y temeroso, comienza a pegar, valiéndose de abundante cantidad de cola vinílica, pelo por pelo, hasta que la calva de la muñeca queda cubierta por una profusa cabellera rubia. Pero disconforme con el trabajo que ha hecho, extrae, del fondo de un bolso de mano deslucido por el uso, una tijera microdentada y, entusiasmado con emular el corte carré de Irupé en el pelo lanífero de la muñeca, efectúa algunos cortes desprovistos de exactitud, que con esmero habrá de intentar disfrazar (2006: 11).

En este caso, el impulso de Virgilio de construir la muñeca cobra la forma de una clara sustitución de la persona amada; incluso llega a hacerse sangrar la lengua para que al lamerla tenga algún gusto parecido a la original. La prueba es que cuando llega el momento de retornar a su casa, Virgilio toma la decisión de tirar la muñeca durante el trayecto al aeropuerto (2006: 64). Su obsesiva concentración en el objeto sustitutivo y su reclusión absoluta tienen su equivalente en un lenguaje oclusivo, lleno de términos en desuso, una especie de lenguaje obsesionado consigo mismo y dudoso de su poder expresivo. Como la muñeca que tiene entre manos Virgilio, el castellano utilizado por el narrador es artificial, de inquietante parecido al idioma originario, pero a la vez distante de su imagen natural, como una muñeca de cera cuya contemplación nos permite regresar al pasado.

En otro supuesto de cosificación con fines psicológicos, Ana María Matute utiliza en Pequeño teatro (1954) la representación habitual de las muñecas, como algo frío y en parte deshumanizado, para caracterizar a un personaje, Zazu. Según señalase Janet Pérez, «el énfasis sobre lo inanimado (las repetidas alusiones al cristal, la transparencia, el vacío y el frío), parte de una modificada técnica expresionista», con la que Matute intenta «sugerir que es más muñeca que ser humano, lo cual sirve para comunicar parte de su radical enajenamiento» (1984: 29). En casos como éste se utiliza la diferencia entre lo real y lo objetual como medio de expresar la poca calidez humana de un personaje, atribuyéndole características jugueteras. 
Como vemos, es una tendencia habitual integrar al motivo de las muñecas dentro de un imaginario femenino, pues, como hemos visto, la mayoría de los ejemplos citados hacen referencia a muñecas o mujeres autómatas, siendo menos frecuentes los antropomorfos varoniles. Como comenta Patrick J. Gyger,

\footnotetext{
Puede ser que, ciertamente, los autómatas no tengan de la vida sino una apariencia y que la posean por una conciencia apreciada por el dualismo cartesiano. Por lo mismo, no son más que apariencia, lo que significa que en ocasiones transmiten una imagen más fuerte que lo real: en efecto, pueden tomar una forma que se corresponde perfectamente con nuestros deseos. Y si «el hombre hizo al hombre a su imagen y semejanza», como escribió Norbert Wiener, dio forma especialmente a la mujer según su fantasía. No es, pues, de extrañar que una de las primeras criaturas artificiales de las que hablaron los mitos antiguos sea Galatea, la estatua creada por Pigmalión (2009: XI).
}

Teniendo en cuenta que una de las características de las muñecas, sobre todo en la era industrializada, es la serialización mercantil, que hace indistinguibles a los juguetes volviéndolos copias, se advierte en Quintana -y también en las muñecas manufacturadas de Rosario Ferré, o en la muñeca de goma creada sobre la imagen de Delphine en la novela de Juan Francisco Ferré- una voluntad de resistir al borrado de la subjetividad, personalizando o «customizando» la muñeca, en aras de su hipersubjetivación para convertirla en fetiche, como veía Hoyos (2016: 462) en la novela de Ariel Magnus. Hay, en consecuencia, un paradójico movimiento de doble vuelta entre la cosificación y la personificación a ultranza (el personaje olvida o aparta a la mujer real, pero crea o encarga una figura que la representa con el fin de amar a esa figura), que delata la voluntad de estos relatos de representar la obsesión enfermiza de los personajes con sus mujeres fetichizadas.

\section{Conclusiones}

Dicen que algunas muñecas se han quedado sin brazos de tanto saludar al mundo.

Aitor Francos en Morante (2016: 204)

A la vista de todo lo anterior, podemos distinguir tres funciones básicas de la aparición de la mujer bajo forma de muñeca: la idealización, mediante la simple repetición del ideal de belleza; la cosificación, a través de la imagen de la muñeca reificada en instrumento de venganza o en muñeca de plástico con finalidad sexual; y la mezcla de esas dos funciones en una tercera, la simbolización, que es una cosificación textual utilizada por los autores para sugerir una abstracción simbólica de propiedades humanas atribuidas a un objeto antropomorfo concreto, a un eidolon. Esas me parecen sus funciones, en todos estos textos de literatura hispánica que hemos ido recorriendo.

Pero cabría preguntarse el porqué de todas estas personificaciones, para hacer sentido de tanta abundancia en la actualidad. Tras todas estas muñecas parecen latir una tendencia reciente (el gusto por el simulacro técnico o artificial), y, más allá y de modo más profundo, dos pulsiones ancestrales: la primera, la de imitar a Dioscomo Prometeos creadores de vida ficticia, capaces de reduplicar las victorias y angustias de la mostrenca existencia; la segunda, no menos importante y ligada con ésta, la pulsión de habitar subjetividades en las que podamos permanecer, continuando la vida por otros 
medios, en otros cuerpos, donde mantener algo de nuestra conciencia, porque aunque seamos de puertas para fuera presuntuosos científicos monistas del siglo 21, sabedores de que no hay distinción entre mente y cuerpo, en el fondo de esa psique paleolítica y reptiliana que nos domina cuando estamos a solas quizá somos aún pequeños dualistas cartesianos, primates temerosos con miedo a desaparecer sin dejar huella. Esos muñecos, esas representaciones virtuales o ficcionales, son el testimonio de nuestra incompletud, y de nuestra voluntad inquebrantable de vivir más, de vivir en otros, de vivir siempre, aunque sea en vidas de mentira.

\section{Referencias bibliográficas}

ACosTA, Jazmín (2012): «Espectrogramas (pos)modernos: el mito zombi en el horizonte de lo "posthumano"», en J. ACosTA et alii, Antología del ensayo filosófico joven en Argentina. Buenos Aires, Fondo de Cultura Económica, pp. 17-34.

Agamben, Giorgio (2005): Profanaciones. Buenos Aires, Adriana Hidalgo.

AlEXIÉvich, Svetlana (2016): Los muchachos de zinc. Voces soviéticas de la guerra de Afganistán. Trad. de Yulia Dobrovolskaia y Zahara García González. Barcelona, Debate.

ANDERSEn, Hans Christian (2004): El soldadito de plomo. Madrid, Anaya Educación.

APOLODORO (1985): Biblioteca. Trad. de Margarita Rodríguez de Sepúlveda. Madrid, Gredos.

AumOnT, Jacques (1992): La imagen. Barcelona, Paidós.

BALLESTRIERO, Roberta (2016): «Desde la contorsión de la realidad a lo siniestro: el incómodo hiperrealismo de maniquíes, muñecas, efigies y figuras de cera», Brumal, 4/2, pp. 93-115.

BAZARRA T., Vania(2010): (In)subordinadas. Raza, clase y filiación en la narrativa de mujeres latinoamericanas. Santiago de Chile, RIL Editores.

BENJAMIN, Walter (2005): El libro de los pasajes. Madrid, Akal.

BRIONES, María Paulina (2013): «Dos microrrelatos», Guaraguao, 18/44, pp. 188-192.

BUENAVENTURA, Ramón (2013): NWTY. Madrid, Alianza.

Bueno Gómez-Tejedor, Sonia y Peirano, Marta, eds. (2009): El rival de Prometeo. Vidas de autómatas ilustres. Madrid, Impedimenta.

CALABRESE, Omar (1990): La era neobarroca. Madrid, Cátedra.

Campobello, Nellie (2000): Cartucho. Relatos de la lucha en el norte de México. Prólogo y cronología de Jorge Aguilar Mora. México D. F., ERA.

CAPARRÓS, Martín (2008): A quien corresponda. Barcelona, Anagrama.

CAREAGa, Delfina (1975): Muñeca vestida de azul. México D.F., Editorial Samo.

CEBRIÁN, Mercedes (2011): La nueva taxidermia. Barcelona, Mondadori.

- (2014): El genuino sabor. Barcelona, Literatura Random House.

- (2016): Malgastar. Córdoba: La bella Varsovia.

Cervantes, Miguel de (1994): Segunda parte del ingenioso caballero Don Quijote de la Mancha. Barcelona,RBA. 
Tropelías. Revista de Teoría de la Literatura y Literatura Comparada, número extraordinario 2 (2017) 279

Vidas de mentira: funciones sustitutivas y simbólicas de las muñecas en algunos ejemplos...

Cilleruelo, José Ángel (1997): Barrio Alto. Madrid, Huerga y Fierro.

CORTÁZAR, Julio (1969): Último round. México D.F., Siglo XXI.

Couve, Adolfo (2003): Narrativa completa. Santiago de Chile, Seix Barral.

Cubillo de Aragón, Álvaro (2016): Las muñecas de Marcela. Universidad Complutense de Madrid (última consulta, 12-12-2016)

Deleuze, Gilles (1989): El pliegue. Barcelona, Paidós.

ESTEBAN ERLÉs, Patricia (2012): Casa de muñecas. Madrid, Página de Espuma.

FERRÉ, Rosario (2002): «La muñeca menor», en José Miguel OvIEDO, ed., Antología crítica del cuento hispanoamericano del siglo XX (1920-1980). Madrid, Alianza, pp. 271-282.

FERNÁNDEZ GONZALO, Jorge (2011): Filosofía zombi. Barcelona, Anagrama.

FERnÁnDEZ MALLO, Agustín (2014): Limbo. Madrid, Alfaguara.

FREUD, Sigmund (1919): «Lo siniestro», en Julián JimÉNEZ HEFFERnAN y J. M. CUESTA ABAD, eds., Teorías literarias del siglo XX. Una antología. Madrid, Akal, 2005, pp. 660-682.

FuENTES, Carlos (1964): Cantar de ciegos. México D.F., Joaquín Mortiz.

GALINDO, Bruno (2012): El público. Madrid, Lengua de Trapo.

GArcíA, Eduardo (2017): La lluvia en el desierto. Poesía completa (1995-2016). Sevilla, Fundación José Manuel Lara.

GARcía LAO, Fernanda (2014): Fuera de la jaula. Buenos Aires, Emecé.

GIRARD, René (1983): La violencia y lo sagrado. Barcelona, Anagrama.

Gómez TruebA, Teresa y MoRÁn RodríGueZ, Carmen, eds. (2017): Hologramas. Realidad y relato del siglo XXI. Gijón, Trea.

GómeZ De la SeRnA, Ramón (1986): La sagrada cripta del Pompo. Madrid, Trieste.

GuAsch, Anna Maria (2000): El arte último del siglo XX. Del posminimalismo a lo multicultural. Madrid, Alianza Forma.

GYGER, Patrick J. (2009): «Introducción», en Sonia BuENo GóMEZ-TEJEDOR y Marta PEIRANO, eds., El rival de Prometeo. Vidas de autómatas ilustres. Madrid, Impedimenta, 2009, pp. IX-XVI.

HAN, Byung-Chul (2014): Psicopolítica. Barcelona, Herder.

Hoyos, Héctor (2016): «Materia prima e historia en Muñecas», Cuadernos de literatura 20/40: 453464.

IBÁÑEZ, Andrés (2014): Brilla, mar del Edén. Barcelona, Galaxia Gutemberg.

KANDEl, Eric R. (2013): La era del inconsciente. La exploración del inconsciente en el arte, la mente y el cerebro. Barcelona, Paidós.

KLEIST, Heinrich von (2005): Sobre el teatro de marionetas y otros ensayos de arte y filosofía. Trad. de Jorge Riechmann. Madrid, Hiperión.

LAPIDO, Paula (2015): Horror vacui. Madrid, Salto de Página.

Machado, Antonio (1972): Poesías. Buenos Aires, Losada.

MARTínEZ, Erika (2017): Chocar con algo. Valencia, Pre-Textos.

Mesa Gancedo, Daniel (1999): «Presentación», Salina. Revista de Lletres 13, pp. 22-23. 
MiLlás, Juan José (2008): Los objetos nos llaman. Barcelona, Seix Barral.

MoRANTE, José Luis, ed. (2016): Re-generación. Antología de poesía poética (2000-2015). Granada, Valparaíso.

NoGUEROL, Francisca (2013): «Barroco frío: simulacro, ciencias duras, realismo histérico y fractalidad en la última narrativa en español», en Jesús MONTOYA JUÁREZ y Ángel ESTEBAN, eds., Imágenes de la tecnología y la globalización en las narrativas hispánicas. Madrid, Iberoamericana Vervuert, pp. 17-32.

OCAMPO, Silvina (1970): Los días de la noche. Buenos Aires, Sudamericana. (2003): Antología esencial. Barcelona, Emecé.

ORECCIA HAVAS, Teresa (2016): «Artistas y antropólogos: estéticas, objetos y diagnóstico cultural en la novela argentina contemporánea», Cuadernos de literatura, 20/40, pp. 325-351.

ORTEGA, José (1984): La estética neobarroca en la narrativa hispanoamericana. Madrid, José Porrúa.

ORY, Carlos Edmundo de (1975): Diario (1944-1956). Barcelona, Barral.

PAZ SoldÁn, Edmundo (2009): Los vivos y los muertos. Madrid, Alfaguara.

PEDRAZA, Pilar (2012): «De Eva futura a Futura de Metrópolis», en Fernando BRONCANo y David HeRnÁNDEZ DE LA FuENTE, eds., De Prometeo a Frankenstein. Autómatas, ciborgs y otras creaciones más que humanas. Madrid, Ediciones Evohé, pp. 143-54.

PÉREZ, Janet (1984): «Variantes del Arquetipo Femenino en la Narrativa de Ana María Matute», Letras Femeninas, 10/2, pp. 28-39.

Perezagua, Marina (2011): Criaturas abisales. Barcelona, Los Libros del Lince.

QuintAnA, Ramiro (2006): El intervalo. Buenos Aires, Tantalia.

RILKE, Rainer María (1999): «Muñecas», Salina. Revista de Lletres13, pp.23-28.

SÁnCheZ-Ostiz, Miguel (2015): Perorata del insensato. Pamplona, Pamiela.

SIBILIA, Paula (2006): El hombre postorgánico. Cuerpo, subjetividad y tecnologías digitales. Buenos Aires, Fondo de Cultura Económica.

TwaIn, Mark (2007): El forastero misterioso. Madrid, Siruela.

Williams, Tennessee (2007): The Collected Poems of Tennessee Williams. New York, New Directions Publishing. 